\title{
Impact of Rewards System on Employee Motivation: A Study of a Manufacturing Firm in Oman
}

\author{
Zaha Noor \\ Researcher/Student \\ Middle East College \\ Muscat, Oman \\ E-mail: 18f18277@Mec.Edu.Om \\ Nishatnaz Nayaz \\ Researcher/Student \\ Middle East College \\ Muscat, Oman \\ E-mail: 18fI7794@Mec.Edu.Om \\ Vrushabh Solanki \\ Researcher/Student \\ Middle East College \\ Muscat, Oman \\ E-mail: I8fI8I13@Mec.Edu.Om \\ Adarsh Manoj \\ Researcher/Student \\ Middle East College \\ Muscat, Oman \\ E-mail: I8fI7767@Mec.Edu.Om \\ Arti Sharma \\ Professor \\ Middle East College \\ Muscat, Oman \\ E-mail: Arti@Mec.Edu.Om
}

Received: June 25, 2020

Accepted: July 05, 2020

Online Published: August 05, 2020

doi: I0.4628I/ijbmf.v4i2.692

URL: https://doi.org/I0.4628I/ijbmf.v4i2.692692

\begin{abstract}
This paper illustrates the importance of employee motivation and the influence of reward and recognition program on the motivation and performance of the manufacturing and production workers of a manufacturing firm situated in the Sultanate of Oman. The goal of the report is to depict the predominant effect of reward and recognition on overall productivity, performance, and motivation. The data gathered for the research was through an exploratory research design wherein the survey questionnaire was distributed to a population of 30 respondents through a stratified sampling technique. Both the qualitative and quantitative data were considered while concluding the major findings, followed by proposing suggestions to improve the motivation levels of employees and enhance their rewards and recognition program.
\end{abstract}

Keywords: Rewards, Recognition, Motivation, Importance, Productivity, Satisfaction. 


\section{Introduction}

\section{I.I Introduction to the Research}

This study emphasizes on the significance of employee motivation and the impact of rewards system on employees' motivation, satisfaction, and performance. These factors crucially influence the efficiency and profitability of a firm. Motivation is a drive that influences people to work hard. It is vital to boosting productivity and performance (Korlen, Essen, Lindgren, Wahlin, \& Schwarz, 2017). A reward is a tool to recognize an employee for doing an exceptional job. It promotes the perpetual improvement of performance that leads to career growth and a boost of morale (Ngwa, Adeleke, Agbaeze, Ghasi, \& Imhanrenialena (2019). This topic revolves around a manufacturing firm in Oman. The company deals with unmotivated staff and dissatisfaction from work, which leads to further problems. Hence, the root cause of the problem needs to be studied, in order to take appropriate measures. Many motivational theorists previously acknowledged that employee's motivation influences their performance. Therefore, it is essential to utilize adequate resources to motivate them and make them feel valued (Rai, Ghosh, Chauhan, \& Sing, 2018).

\section{I.2 Aim and Objectives of this Research}

The aim and objectives of this paper are to recognize and comprehend the significance, and effect of remuneration and recognition programs on the organization. To show that appreciating and rewarding the staff can predominantly influence the association's overall performance and productivity. Rai et al. (2018) analyzed how rewarding and recognizing the staff for their hard work, boosts their motivational levels and builds loyalty, which leads to long term employee retainment.

\section{I.3 Research Design}

The duration for conducting this study was about three and a half months. Both, primary and secondary data was used to complete this paper. Secondary data consisted of journal articles, whereas primary consisted of a questionnaire. The sample size for the questionnaire consists of thirty employees from the manufacturing firm.

\section{I.4 Importance of Research}

This article accentuates the value of motivation in the workplace. Organizations and researchers can refer to this project for enhancing their company performance. It will help the management understand the importance that the company provides not only to the customers but must also acknowledge their employees. This project will help future research to understand the consequences of unmotivated employees and the strategies to tackle these issues. The employees can also get a better understanding on the strategies applied and how they can adjust accordingly.

\section{Research Design}

\section{I Research Design}

This research explores the difficult situations and experiences of the employees which is why exploratory research has been chosen. Their opinions and feedback from the foundations of the research. Exploratory Study is a method that helps the researchers to get answers to primary research questions by using organized data collection techniques that provide the required and expected responses to the primary questions (Bispo, 2019). The qualitative data approach was involved as it pertains to the insight issues and the understanding through human interactions. Qualitative research allows us to see the larger picture and helps us to answer the conditional problems of the organization. This research design helps to explore employee-work relationship vastly. The exploratory study creates room for us to describe our own preferences and ideas about the whole situation. The main aspect of this research study is that it helps us to frame and respond to the ethical considerations of the project. This type of study helps to understand the participant's point of view on a large scale. The perceptions of people cannot be measured and therefore this type of qualitative data requires exploratory study as our research tool.

\subsection{Population, Sample Size, and Sampling Technique}

The studied organization has a population of around 70-80. A sample is defined as the specific amount of people that you study or observe from your total population (McCombes, 2019). There are various sampling techniques used over time. Sampling is divided into 2 forms - probability and non-probability sampling. Probability sampling is further divided into 4 forms (McCombes, 2019). The first form is known as Simple random sampling, the second is known as Systematic sampling, the third is known as stratified sampling and the last is known as cluster sampling (McCombes, 2019). The sampling technique used for this research was stratified sampling. Stratified sampling is used when a mixed sample is used. Meaning, people with different characteristics, ages, incomes, etc. Stratified sampling then divides these different characteristics of people and makes them in selected groups of people with the same age, gender, income, and so on. This technique made the data collection process easier and the research more identifiable and understandable. The sample size for the study was 30 out of which 20 were males and I0 were females. 


\subsection{Research Instrument and Data Analysis Techniques}

A research instrument is the tool used to collect data for the research project. The research instruments used in this research paper is a questionnaire. A questionnaire is one of the most common instruments used for collecting data (Yang, Liu, \& Xie, 2019). A questionnaire is a set of questions that are answered by the respondents to help the researchers acknowledge the study more accurately. The questionnaire has numerous advantages and one of the most common ones is the anonymity of their respondents. This helps the respondents to be more open about their opinions. It is also cheap, gives faster results, and is easy to analyze. The questionnaire does have a few setbacks like misunderstanding of the questions by the respondents. Open-ended questions can take more time to analyze and process, which also becomes a drawback.

The data analysis technique is divided into two parts, quantitative and qualitative data. Quantitative data consist of data acquired from the questionnaire (Yang, Liu, \& Xie 2019). This data is analyzed statistically with the help of MS Excel and PSPP software. Furthermore, it is presented in the form of pie charts and bar charts. This form of data is said to be non-biased because it is statistical. Qualitative data consist of data acquired from the interview. This data is examined through content analysis. This is non-numerical data that can be observed and recorded. Qualitative data assist in providing rich data due to the open-ended questions and it also gives an in-depth analysis to the research. Although, both types of data have a very different approach, they are equally vital to conduct the research.

\section{Literature Review}

\section{I. What is Rewards System?}

An employee reward system comprises an organization's coherent strategies, procedures and, system for recognizing the employee in terms of their involvement, skills and, potential and their market value. This system is created within the structure of the organization's reward beliefs, strategies, and policies. It consists of an arrangement in the framework of 'progression, routine, structure' that will impart and perpetuate the apt type and level of 'pay, benefits and, other forms of reward. The reward system intends to 'attract, retain, and motivate' the workforce (Wasiu, \& Adebajo, 20I4). This system plays a vital role in ensuring employee engagement by providing each individual with the most suitable motivational factor. Since every individual has different needs and goals, they are driven by different sets of motives, as some may seek a bonus whereas others may desire a sense of recognition or a promotion to a higher post. Thus, these factors influence their performance, behavior, and commitment to the job. Henceforth, developing a reward system that caters to every employee's needs is extremely crucial (Bhattacharya $\&$ Mukherjee, 2009).

\subsection{Importance of Rewards System}

The employees are the backbone of an organization. Thus, an organization achieves its goals only when the employees are determined to work harder and contribute towards the end goal. This determination arises from a desire to achieve a personal target that is aligned with their job. Rewards are a link between these personal goals and their motive to work.

When the staff feels they are justly rewarded for their ability, expertise, intellect, and involvement, they are considered to be satisfied with their job, resulting, they perform better at their job (Bhattacharya \& Mukherjee, 2009). Factors such as providing a bonus on achieving more than the target sales and recognizing their work and praising them are rewards that motivate an employee. This satisfaction of work helps to retain the staff and maintain the employee turnover. (Ngwa et al., 2019) stated in their research paper that, frequent distribution of rewards and appreciation improves their performance perpetually and provides them with a sense of accomplishment as well as creates a path for career growth (Ngwa et al., 20I9). In another article written by Bhattacharya and Mukherjee (2019), discussed a more creative approach to reward the staff. The article stated that catering breakfast and lunch or even organizing office trips and parties when goals are achieved, or the business earns profit shows the employees they are valued and keeps them engage. This helps to create a positive work environment as well as attract new talent (Bhattacharya \& Mukherjee, 2009).

\subsection{Types of Rewards Systems}

(Wasiu, \& Adebajo, 2014) categorized rewards into 2 types: Intrinsic rewards and extrinsic rewards. Intrinsic rewards are also known as 'non-financial rewards' that are ingrained to a task and their administration is not determined by the 'presence or actions' of another individual. It includes the feeling of being acknowledged, praised for doing a good job, and participating and being involved in something. Some of the types of intrinsic rewards are- a sense of meaningfulness, sense of choice, sense of growth, and sense of community. On the other hand, extrinsic rewards are financial rewards that are administered by an external agent. It includes financial motivations like money, retirement benefits, health insurance scheme, compensation, salary, bonus, etc. These two types of rewards combined help to keep the employees engaged and motivated at work. Though it is tough to say which type of reward is more important, these two rewards can coexist in the organization, given that there is a balance between the two (Wasiu, \& Adebajo, 2014). As per the current scenario, where countries are going into lockdown and most organizations are adjusting to the new work from home routine, there seems to be a need for the company to reform their rewards system to fit the current needs of the employees. At times like this when the world is going through a global pandemic, 
the workforce needs more of encouragement, stable compensation, and recognition for their performance. Thus, including rewards like promotion may not seem desirable to some right now.

\subsection{Impact of Reward Systems on Employee Motivation}

Employee's work and satisfaction are what determines the level of progress, their performance, and how productive the employee would be in their respective jobs. Taking care of employees is very important because most of the employees may not be happy with their jobs due to many factors like excessive responsibilities and workload, unsatisfactory rewards, etc. Hence interactions and solving problems of employees are important. In many cases, the rewards system is used as a tool to enhance the employee's performance. The main reward system implemented is an increase in salaries and wages which is a monetary aspect of motivation (Pinto \& dos Santos, 2018). Every employee needs a good salary package along with other benefits such as bonuses, allowances, medical claims, etc. But with the corona infection everywhere, the created lockdown situation is making the work progress slow and hard for the employees. Employees are working through internet calls and online video conferences for completing their projects and employees are losing interest because of working in a home environment. But still, the firm is doing its best to provide monetary and non-monetary rewards to keep the employees motivated. Employees are credited with their agreed salaries to their bank accounts to keep the continuous flow of work. When it comes to non-monetary rewards, the first thing is that learning and training opportunities are provided to employees who do not have much knowledge about their area of expertise because this is the best time to improve and motivate employees sitting at their homes which is quite difficult during the normal busy working hours. The second thing is employees are given recognition as they attend meetings and show their best efforts to finish the work during such hard times (Pinto \& dos Santos, 2018).

\subsection{What is Employee Motivation?}

Motivation is defined as the wants or needs inside people that 'motivates' or propels them to work the hardest to accomplish their objectives. Examining employee motivation explicitly then it is characterized as the degree of energy or intrigue shown by a worker to accomplish its organization's objectives and to surpass in their career path. Various researches have been conducted to comprehend employee motivation and what impacts it. Numerous organizations flourish to achieve their employee's motivation by creating various methodologies and strategies. Frequently these administrative techniques created to improve employee motivation achieve in a noteworthy positive change in the association (Korlen et al., 2017). CEO and staff at senior positions are frequently evaluating new strategies by watching worker's behavior and performance and then assessing if the strategy was effective or not. Various researches into employee motivation have demonstrated that motivation can be affected with the assistance of fiscal prizes, strategies such as employee engagement, and so on. However, actualizing these rewards and techniques adequately and decently is a difficult and challenging task for the organization (Korlen et al., 2017).

\subsection{Employee Motivation Theories}

To motivate employees, many organizations acquire strategies with the help of theories. Many theories have been written in a generalized form but in time they have been transferred into certain topics.

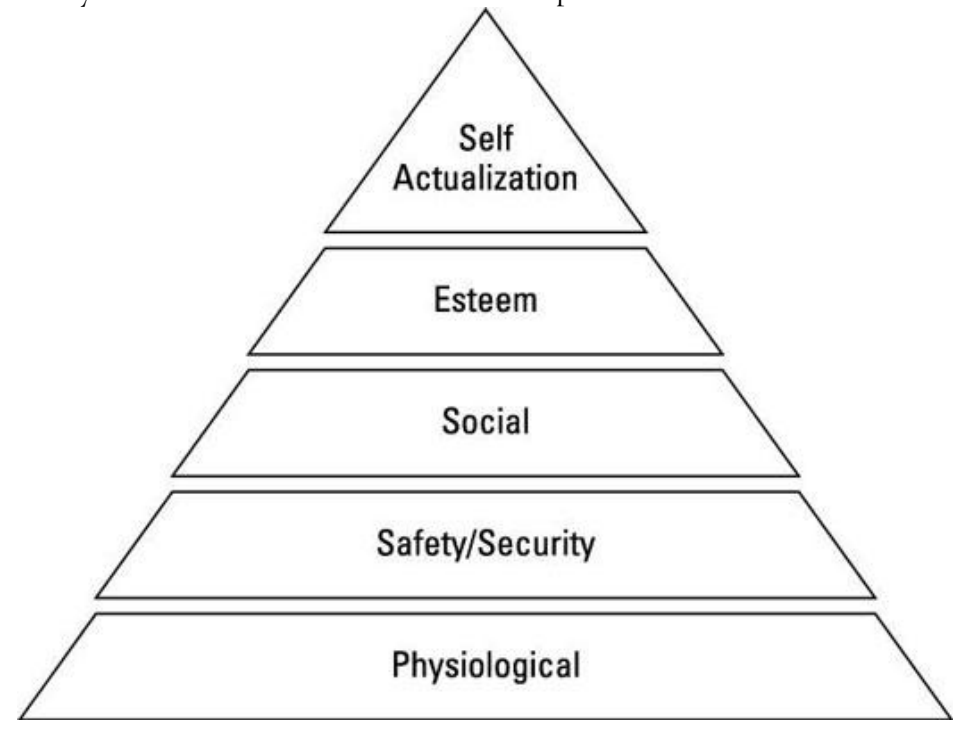

Figure I. Maslow's theory 
One of the most effective theories is Maslow's hierarchy of needs. This hierarchy consists of five categories in a pyramidal structure. These categories consist of different needs to motivate employees. The first stage from the bottom is psychological needs (Č́̌žek, 2012). This stage talks about providing a fair salary. The next stage is security needs, which talk about steady working conditions and benefits. After this comes the social needs and esteemed needs, these stages include social concerns and recognition concerns respectively. The third stage includes the employees having a quality relationship with peers, subordinates and, boss, which are also compatible with each other. The fifth stage is called self-actualized needs which cover the achievement concerns ( $\breve{C}$ í̌ek, 20I2). This includes giving employees more challenging work to self-aware their potential which will lead to motivation. This theory helps in understanding the various stages in motivating employees and in finding out the stages that need to be strengthened.

The second most effective theory for this research is Taylor's scientific management. This theory is one of the first theories written on employee motivation. This theory claims that money is the best substitute for motivating employees (Dobija, Górska, Grossi, \& Strzelczyk, 2019). The theory says that employees don't always enjoy their work which leads them to slack hours. To prevent this issue, their work needs to be broken down so that it is more achievable. Employees should be paid based on the result they bring in the organization. This creates a non-zero-sum game for the employee and the organization.

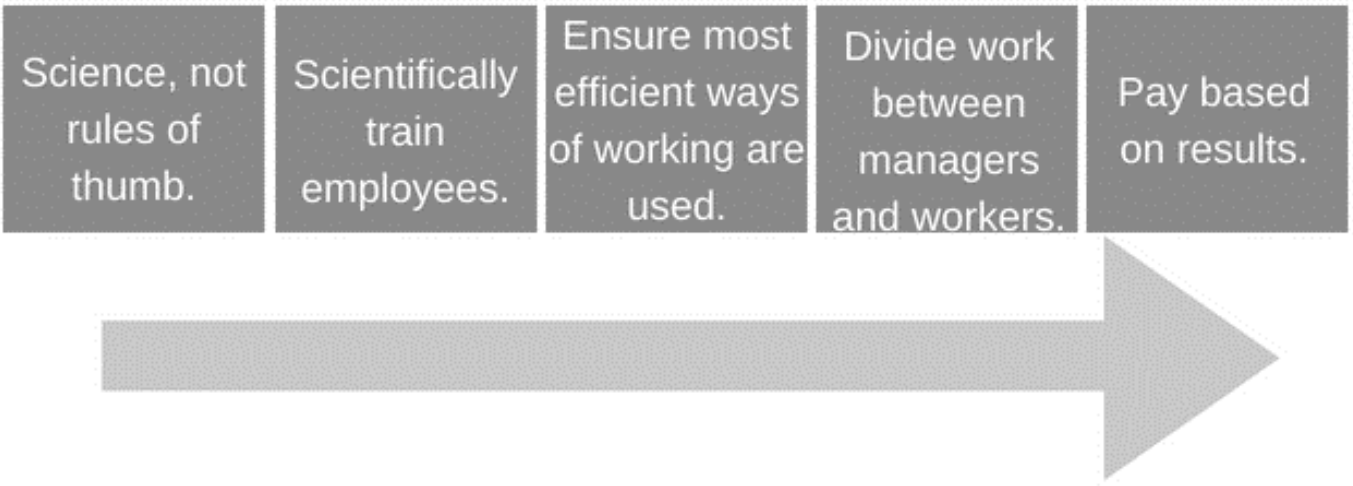

Figure 2. Non-zero-sum game for the employee and the organization

\subsection{Importance of Employee Motivation}

As Gkorezis and Kastritsi (2017) examined in her study, there are numerous benefits of keeping your employees motivated, which makes employee motivation an essential element to run your business smoothly and guarantee organizational success. It is widely acknowledged that employee motivation is directly linked to employee productivity (Korlen et al., 2017). Employees that are motivated about their work tend to work the hardest and fulfill all their responsibilities. Employee motivation affects Organizational performance as a motivated employee is hard-working and will ensure their organizational goals are achieved but de-motivated employee doesn't perform well leading to decline in productivity and profits (Gkorezis \& Kastritsi, 2017). Organizations that take care of their employees' motivation are likely to be more successful and grow as they have the power of strongly motivated employees that will work the hardest in achieving their organization's goals. Employee motivation also boosts creativity and generates innovative ideas which are very beneficial for the organization (Gkorezis \& Kastritsi, 20I7). Employees are the most valuable asset of an organization and to make sure this asset is retained/taken care of it is important to ensure their needs are fulfilled. Employee motivation also plays a significant role in employee retention as when the employee observer's that the organization works hard to ensure employee motivation it makes him/her feel valued giving him or her every reason to work for the organization long term (Korlen et al., 2017).

\subsection{Factors Affecting Motivation}

Motivation is an important aspect of an employee as it helps determines if the employee is satisfied with his/her working condition and shares the same organizational vision. An employee who is satisfied with his/her job would be 'motivated' and is much likely to perform better. Whereas, an unsatisfied employee would need to be pushed to work using different motivational tools and techniques (Kroon, Woerkom, \& Menting, 2017). The first tool presented is rewards and remuneration. Employee satisfaction and remuneration have a direct relationship with each other. The affection towards money is what drives the employees to work better. It is previously known and seen by many motivational theorists and researches that money is the most motivating factor (Kroon et al., 2017) Reward packages do acts as a positive factor that highly affects motivation towards 
employees. If the employees are provided with a higher salary, then that could result in a better performance of the employee. The second strategy or technique advised is changing the leadership style. If the superiors maintain a healthy relationship with the subordinate, then it affects the work progress of the employees as there would be no communication barrier between them. This helps the employees to share their problems and grievances or discuss any difficulty they are facing while working. The superior can find an alternative solution and therefore can motivate the employee by guiding and encouraging the subordinate. There are various other strategies advised that positively affect an employee's motivation such as employee engagement, ob rotation, delegation, and so on (Kroon et al., 2017).

\subsection{Drawbacks of Low Motivation}

Low motivation can cause many issues in an organization. This can lead to companies having a major dip in their performance for some time. One of the major drawbacks of low motivation is a decrease in productivity. An employee slaking of work due to a dip in motivation can lead the entire team in a major fallback in productivity (Giacomelli, Annesi, \& Barsanti, 2019). Just one employee can easily decrease productivity drastically and can influence others as well. An unmotivated employee will have a hard time in overcoming difficulties. A decline in performance is another drawback of low motivation. When an unmotivated employee is given a challenging task, he or she may postpone it subconsciously and move to an easier task without understanding the underlining problem. The employee soon loses their interest in their job and stops caring about being on time to work or in general are not abided to follow organizational rules and regulations (Giacomelli et al., 2019). This leads to higher costs for the business, which means in financially difficult times it could be a difference between going out of business or staying above water. Unmotivated employees come to the workplace with little or no enthusiasm to work. This will steer to working just for their paycheck and nothing more. Over time, they could lose passion for work or at worse feel depressed.

There are various drawbacks to low motivation that can affect not only the employees but the company as well. Due to the current COVID-I9 pandemic crisis, a sense of panic has been created among individuals. The organization needs to tackle this stress to prevent the employees from feeling de-motivated.

\section{IO Effect of Good Reward System on Employee Motivation}

A well organized, fair and, just reward and recognition system positively affects employee motivation. Reward systems help influence employee motivation as the employee feels 'recognized' or seen by their superiors for their hard work (UKEssays 2018). This makes the employee feel valued and appreciated by its association for the hard work he/she puts in and therefore leads to increased motivational levels and increased enthusiasm (UKEssays, 2018). A fair and just reward system also helps build up potential in the employee and pushes the employee to work hard. This usually results in better performance leading to increased employee productivity (UKEssays, 2018). Often, employees do not perform up to their potential or work hard for their jobs because of low interest or motivation to complete their tasks assigned. Therefore, it is important to present the employees with that 'need' or motivating factor that would boost their motivation and desire to complete the task efficiently. Reward systems play a significant role in boosting employees' motivation and giving them the reason to perform better. For instance, a simple target such as increase productivity by $10 \%$ this month would result in bonus that would automatically motivate the employee to achieve this target. Moreover, rewards are not necessarily presented I 'money' form. At times, reward systems are nonfinancial techniques such as employee of the month, an extra day off, and so on. Such rewards also increase the employee's motivational levels as it likely to make him feel valued and respected at his/her workplace.

4. Data Analysis

The following results were received and analyzed with the help of a questionnaire.

\section{I Which of the following factors do you believe causes low employee motivation?}

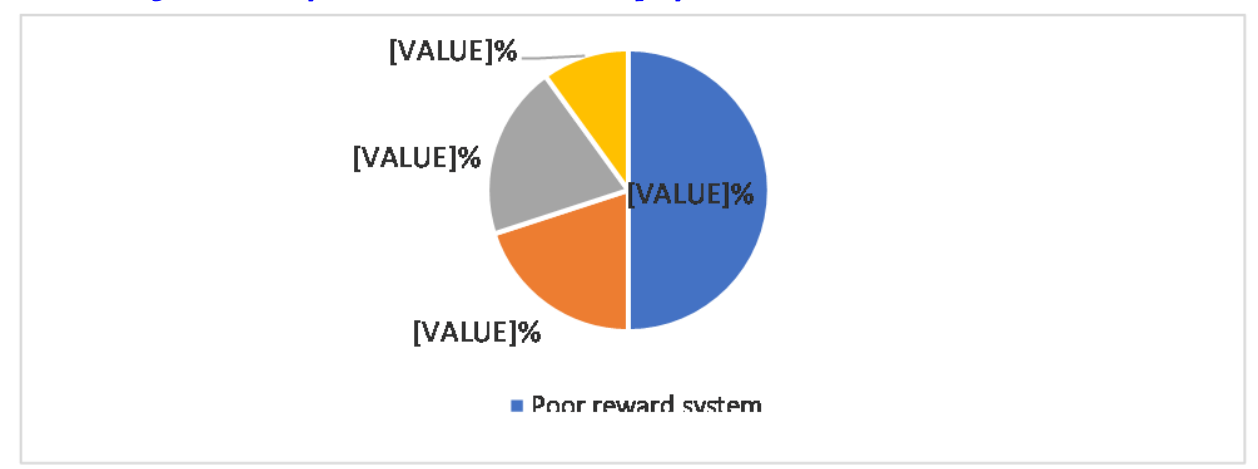

Figure 3. Factors believe causes low employee motivation 
$50 \%$ of the employees feel that a poor reward system is the cause of low employee motivation. A reward system is created to motivate and retain employees (Wasiu, \& Adebajo, 2014). A reward system plays a vital role in keeping employees happy because this system consists of many aspects within it. Dull work environment and long working hours are given $20 \%$ vote each, for the cause of low motivation. According to Maslow's theory, work environment and long working hours can cause de-motivation in the workplace (Č́ž̌ek, 2012). The environment does play a major role in an employee's mindset. Long hours can cause stress to the workers and decline their productivity in the long run.

\subsection{How does motivation impact your performance at work?}

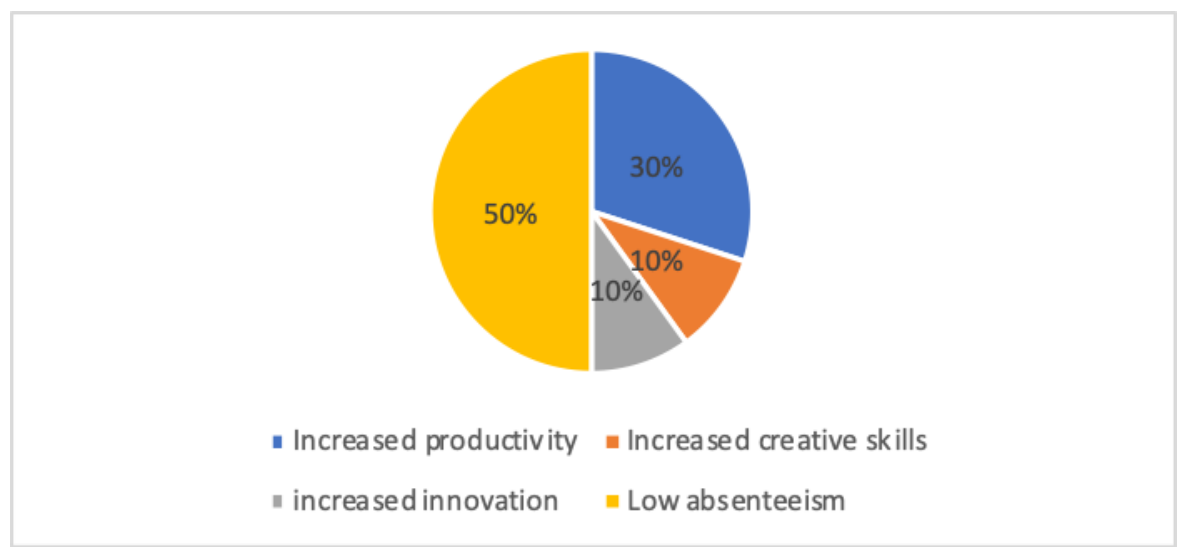

Figure 4. Motivation impact your performance at work

$50 \%$ of the employees feel that absenteeism can be prevented by motivation. Absenteeism can be caused due to neglecting the task assigned (Wasiu, \& Adebajo, 20I4). This shows that the employees feel that motivation impacts enthusiasm the most. If the employees are motivated, then the work feels easier to perform. $30 \%$ of the employees feel productivity increases due to motivation. Motivation in the workplace is created to keep employees productive. Increased creative skills and innovation have both $10 \%$ each. This indicates that employees tend to feel mentally stronger when motivated. Vote on these categories is less because their impact is on a long run only. This data shows that motivation impacts productivity and enthusiasm.

\subsection{In your opinion, which factor would help in increasing employee motivation?}

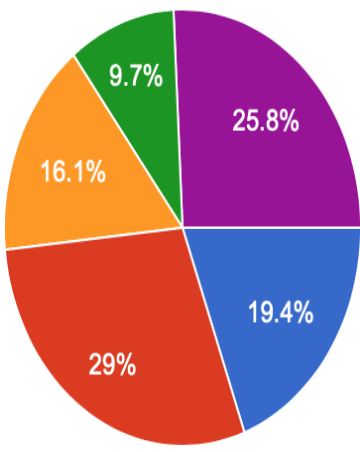

Incentive/ Bonus

Recognition for work

Promotion

Improved work environemnt

All of the above

Figure 5. Factor would help in increasing employee motivation

The data collection assisted that the greatest number of votes were for 'Recognition for work', followed by the second most votes for the option 'All of the above'. As stated by Scott (2019), it is proven that monetary and non-monetary; both types of rewards play a vital role in employee's motivation. This statement is further proved with the help of our research as the majority of the votes were in favor of an improved or new rewards program. 


\subsection{Do you feel that employee motivation is impacted by rewards and recognition system?}
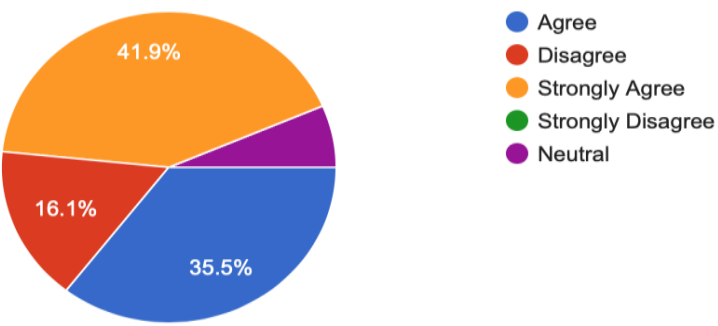

Figure 6. Employee motivation is impacted by rewards and recognition system

Out of 30 respondents of the questionnaire, more than 50\% voted in favor, agreeing to the fact that rewards and recognition program impacts employee motivation. A small percentage of the workers disagreed with the statement and the others went for a neutral option. This data further acknowledges the fact that an employee rewards program is effective in the workplace (McQuerrey, ND).

\subsection{Do you think a good rewards system is essential at the workplace?}

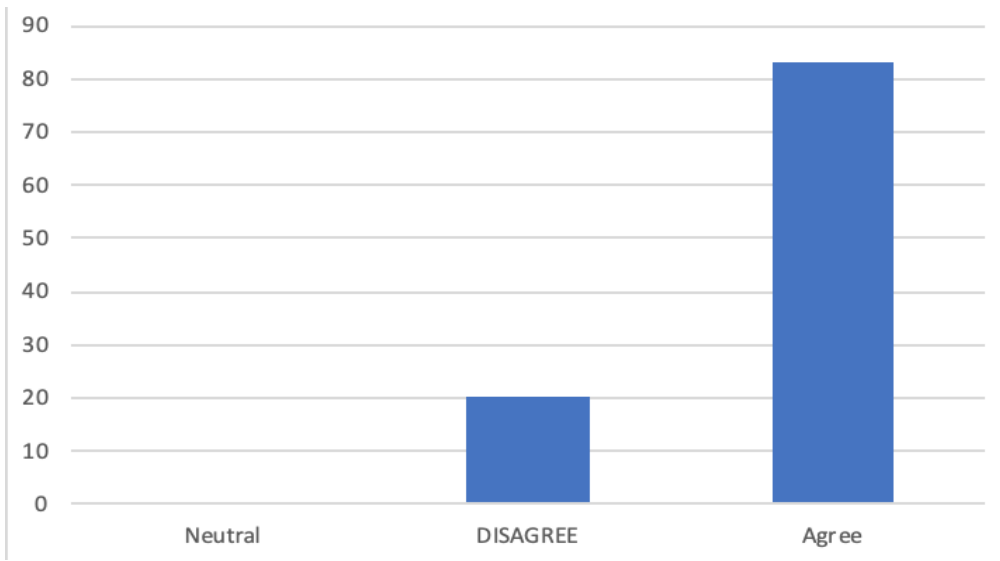

Figure 7. Good rewards system is essential at the workplace

The aim of this question was to highlight the importance of the rewards system and what the employees feel about it. The questionnaire was also answered by a person from the HR department and 3/4th of the respondents agreed to the statement. Only I/4, i.e. 5 people disagreed with the statement and thought a rewards system isn't a necessity for work.

\subsection{How does the rewards and recognition program help you as an employee?}

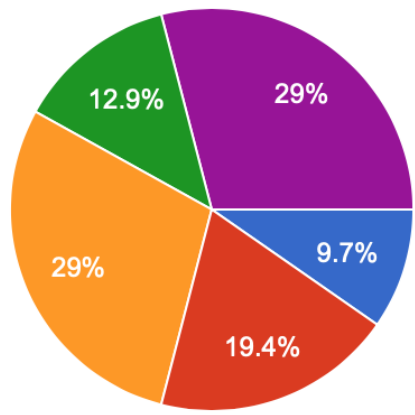

It makes us feel valued

Makes us feel appreciated by our superiors

Makes us feel recognized/seen for our hardworking

Increases employee loyalty/

retainment

All of the above

Figure 8. Rewards and recognition program help you as an employee 
'This was the most important question of all. This question helped acknowledge the employee's point of view, of how rewards and recognition program helps them. From the result gathered, it is seen that more around $29 \%$ voted for 'all of the above' option and the same percentage voted for 'makes us feel recognized' option, whereas the rest of the figures are scattered. Rewards programs bring in about a lot of benefits and positivity apart from increased motivation. The rewards programs also help build employee loyalty which in the future helps for retainment, improved productivity, and so on (Antoni, 20I2).

\subsection{Which of the following is a sign of a poor reward and recognition system?}

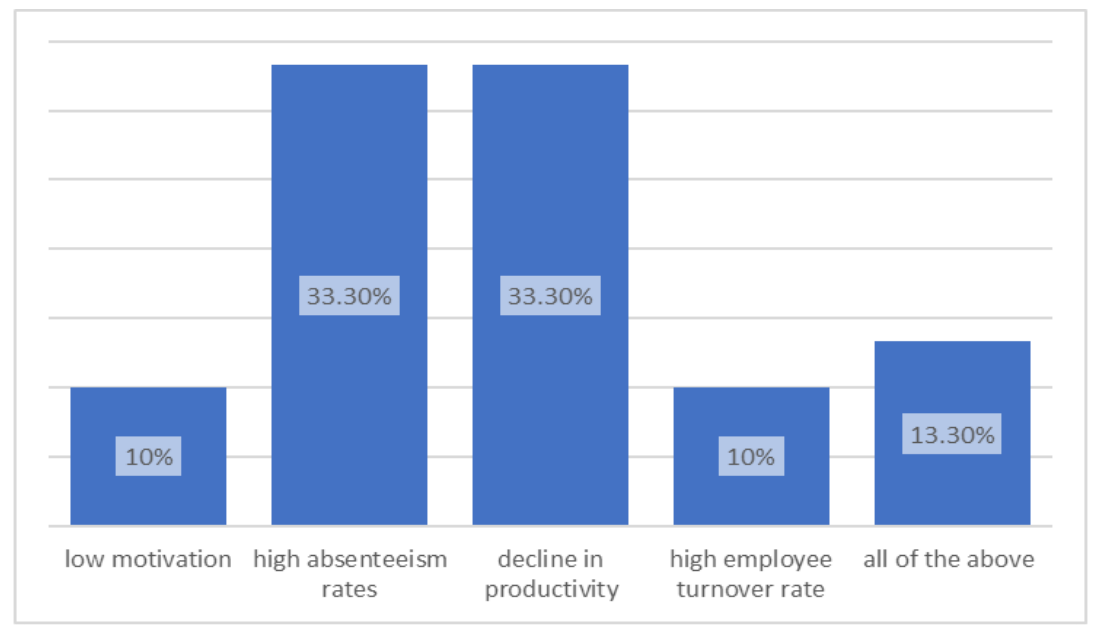

Figure 9. Sign of a poor reward and recognition system

The bar chart indicates "High absenteeism rates" and "decline in productivity" are the most voted categories by attaining 33.3\% votes respectively. "low motivation" and "high employee turnover rate" was the least voted factors with I0\% votes respectively. And the rest $13.3 \%$ believe that all factors stated are an indication. Henceforth, we estimate that high absenteeism and reduced productivity are the highest voted factors because they may have observed the same in their work environment. As in, generally, low motivation is seen as the greatest indication of a poor reward scheme (Pinto \& dos Santos, 2018) which does not seem to be the case here as it was the third least voted factor. Good reward systems boost morale and enhance their performance resulting in, increased productivity and minimal absenteeism rates (UK Essay, 2018).

\section{Conclusion \& Acknowledgements}

From the data collected through the questionnaire, it is seen that the majority of the employees feel that low motivation in the workplace is caused due to poor reward systems. Low motivation in the workplace, leads to many problems such as high absenteeism, decline in productivity, lower profit margins, and so on. Employees feel that motivation can be increased by recognition in work, bonus, and promotion. Moreover, the research also helped to uncover the fact that the employees did not just require improvement in reward systems but also recognition for their contribution of work which the firm gave less importance. Recognition can be provided with the help of basic rewards like employee of the month, employee of the week or employee of the year. The questionnaire helped us understand that low motivation is the main problem of the firm and has deteriorated the scale of work among its employees. The management needs to find a key solution to this problem. It is recommended that organizations look into the development of a rewards system and acknowledge the importance of appreciation of its employees for their hard work.

The writers desire to express their most sincere appreciation and thanks to everyone who helps them for their encouragement and advice through the course of this study and for their help in the preparation and writing of this report. Thanks go to the faculty member of Department of Management Studies and to the Head, Faculty of Department for supplying the source of information for this work. Thanks are also due to super visor for reading and checking the format of this report.

\section{References}

Antoni, H, C. (2012). Guest Editor's Introduction: Reward Management. Journal of International Studies \& Organization, 42 (I), sior\%3A382d6be8c5dc45I20dea97Ifb280246f 
Bhattacharya, S., \& Mukherjee, P. (2009). Rewards as a Key to Employee Engagement: A Comparative Study on I.T. Professionals. ASBM Journal of Management, $2(\mathrm{I}), \quad$ I60-I75. https://search.proquest.com/central/docview/20502I963/fulltextPDF/90EIDI2A5F2I43D4PQ/I?accountid=I 60115

Bispo, M, D, S., \& Gherardi, S. (2019). Flesh-and-blood knowing: Interpreting qualitative data through embodied practicebased research. RASP Management Journal, $54 \quad$ (4), https://www.emerald.com/insight/content/doi/I0.II08/RAUSP-04-20I9-0066/full/html

Č́ž̌ek, P. (2012). The Application of Maslow's Hierarchy of Needs to the Entrepreneur's Motivation - The Example from Region Pardubice. Scientific Papers of the University of Pardubice, I8(24), 43-50. http://web.a.ebscohost.com/ehost/detail/detail?vid=0\&sid=6I9240b3-aa2a-42f8-8d466e75c6ffI a60\%40sessionmgr40068bdata=JkFIdGhUeXB1PWlwLHNzbyZzaXRIPWVob3NOLWxpdmU\%3d\#A $\mathrm{N}=84318018 \& \mathrm{db}=\mathrm{a} 9 \mathrm{~h}>$

Dobija, D., Górska, A. M., Grossi, G., \& Strzelczyk, W. (2019). Rational and Symbolic Uses of Performance Measurement: Experiences from Polish Universities. Accounting, Auditing \& Accountability Journal, 32(3), $750-781$. https://www.emerald.com/insight/content/doi/I0.II08/AAAJ-08-20I7-3I06/full/html

Giacomelli, G., Annesi, N., \& Barsanti, S. (2019). Combining Ideal Types of Performance and Performance Regimes. International Journal of Public Sector Management, $32(7), \quad$ 72I-740. https://www.emerald.com/insight/content/doi/I0.II08/IJPSM-I I-20I8-0246/full/html

Gkorezis, P., \& Kastritsi, A. (2017). Employee expectations and intrinsic motivation: work-related boredom as a mediator. 39 (I),

IOO-II I http://0sI02j336.y.https.www.emerald.com.mec.proxy.deepknowledge.io/insight/content/doi/I0.I I08/ER-022016-0025/full/pdf?title=employee-expectations-and-intrinsic-motivation-work-related-boredom-as-a-mediator

Korlen, S., Essen, A., Lindgren, P., Wahlin, A, I., \& Schwarz, T, U. (2017). Managerial Strategies to make incentives meaningful and motivating. Journal of Health Organisation and management, $3 \mathrm{I}$ (2), I26-I4I. https://www.emerald.com/insight/content/doi/I0.II08/JHOM-06-2016-0I22/full/pdf?title=managerialstrategies-to-make-incentives-meaningful-and-motivating

Kroon, B., Woerkom, V, M., \& Menting, C. (2017). Mindfulness as a substitute for transformational leadership. Journal of $\begin{array}{llll}\text { Managerial Psychology, } & 32 & \text { (4), } & \end{array}$ http://0sI02jenc.y.https.www.emerald.com.mec.proxy.deepknowledge.io/insight/content/doi/I0.II08/JMP-072016-0223/full/html

McCombes, S. (2019). Understanding different sampling methods. https://www.scribbr.com/methodology/samplingmethods/

McQuerrey, L. (ND). Effectiveness of Employee rewards program. https://smallbusiness.chron.com/effectiveness-employeerewards-programs-48649.html

Ngwa, W.T., Adeleke, B.S., Agbaeze, E.K., Ghasi, N.C., \& Imhanrenialena, B.O. (2019). Effects of Reward System on Employee Performance among Selected Manufacturing Firms in the Litoral Region of Cameroon. Academy of Strategic $\begin{array}{lll}\text { Management Joumal, } & \text { I8(3) I-I6. }\end{array}$ https://search.proquest.com/pqdtglobal/docview/2294437017/fulltextPDF/3EB5A94B8E874827PQ/I?accounti $\mathrm{d}=$ I60I I5

Pinto, L. F. S., \& dos Santos, C. D. (2018). Motivations of crowdsourcing contributors. Innovation and Management Review, I5

58-72. http://0sI02jenc.y.https.www.emerald.com.mec.proxy.deepknowledge.io/insight/content/doi/I0.II08/INMR-022018-004/full/html\#sec002

Rai, A., Ghosh, P., Chauhan, R., \& Sing, R. (2018). Improving in-role and extra-role performances with rewards and recognition. Journal of Management research review, 4I (8), 902-919. https://www.emerald.com/insight/content/doi/I0.II08/MRR-I2-20I6-0280/full/pdf?title=improving-in-roleand-extra-role-performances-with-rewards-and-recognition-does-engagement-mediate-the-process

Scott, S. (2019). Rewards and Incentive in the workplace. https://smallbusiness.chron.com/rewards-incentives-workplaceI I236.html

UKEssays. (2018). Effect of Rewards on Employee Motivation. https://www.ukessays.com/essays/business/a-study-on-theimpact-of-rewards-on-employee-motivation-in-the-telecommunication-sector-of-pakistan-business-essay.php\#citethis

Wasiu, B.O., \& Adebajo, A.A. (2014). Reward System and Employees Performance in Lagos State (A Study of Selected Public Secondary Schools). Kuwait Chapter of the Arabian Journal of Business and Management Review, 3(8), I4-28. https://search.proquest.com/pqdtglobal/docview/I527308089/fulltext/8I3CD8F4545B47E5PQ/I ?accountid=I 60115 
Yang, Y., Liu, S., \& Xie, N. (2019). Uncertainty and Grey Data Analytics'. Marine Economics and Management. 2(2), 73-86. https://www.emerald.com/insight/content/doi/I0.II08/MAEM-08-20I9-0006/full/html

\section{Copyrights}

Copyright for this article is retained by the author(s), with first publication rights granted to the journal. This is an open-access article distributed under the terms and conditions of the Creative Commons Attribution license (http://creativecommons.org/licenses/by/4.0/). 